\title{
Decision Support System for Selecting Cooperation Forms between a Higher Educational Institution and a Potential Student
}

\author{
Zakharova Alexandra \\ Yurginsky institute of technology \\ National Research Tomsk Polytechnic University \\ Tomsk, Russia \\ aaz@tpu.ru
}

Alexandrov Artem

Yurginsky institute of technology

National Research Tomsk Polytechnic University

Tomsk, Russia

artemka7474@mail.ru

\author{
Fisochenko Oksana. \\ Yurginsky institute of technology \\ National Research Tomsk Polytechnic University \\ Tomsk, Russia \\ giri@rambler.ru
}

\begin{abstract}
The article deals with some challenges concerning decision support system (DSS) development for selection of a cooperation form between a higher educational institution and potential students. Nowadays Russian higher educational institutions have to compete with each other to attract best potential students to their educational programs. The selection of the most effective cooperation forms with potential students is a problem for higher educational institutions. For better results University activities should be targeted, meet individual peculiarities of potential students. The paper proposes to select a cooperation form with a glance to potential students' ability to study the programme. We have worked out a conception of an automated decision support system for selection of a cooperation form between a higher educational institution and a potential student. We have developed software for DSS main functions: 1 . Evaluation model for assessing applicants' ability to study IT programmes on the basis of a discriminant analysis method; 2 . Evaluation model for assessing activity effectiveness to select an appropriate activity set for applicants potentially able to study a particular programme. To approbate a proposed approach with the help of DSS we have done an experimental study to select some cooperation forms between Yurga Institute of Technology, Tomsk Polytechnic University affiliate (YuTI TPU) and applicants potentially able to study IT programmes.
\end{abstract}

Keywords-potential students; educational programmes; selection; cooperation forms; activities Introduction.

\section{INTRODUCTION}

Nowadays in the context of the Russian education modernization one of the main public policy directions is professional education quality improvement. The content of educational programmes must ensure personality formation, capacity for self-development and changing their professional direction.
At the present moment the education service market is loaded with high educational institutions and educational programme supply. Every University is interested in attracting best potential students motivated to study their educational programmes [1]. To reach this goal Universities hold a wide range of activities aimed at cooperation between a higher educational institution and potential students. Usually when selecting a cooperation form they do not take into account individual peculiarities of potential students (for example their ability to study technical sciences or humanities) [2-6]. It makes held activities less effective. That is why a crucial task is method development for assessing alternatives to cooperation forms between higher educational institutions and potential students with respect to their individual peculiarities.

The problem is absence of methodological basis for selecting a cooperation form between a higher educational institution and potential students. To solve the problem we propose to develop a decision support system which ensures evaluation of cooperation forms with a glance to individual peculiarities of applicants, monitoring and assessment of held activity effectiveness.

\section{OBJECTIVES, METHODOLOGY AND RESEARCH DESIGN}

During the research it is established that there is no methodology and software for decision-making support when selecting a cooperation form between the University and potential students.

The study goal is to develop the decision support system for selecting a cooperation form between a higher educational institution and a potential student.

The study aims are: 
1) To develop a decision support system conception for selecting cooperation forms between a higher educational institution and a potential student on the basis of an author decision support scheme;

2) To develop software for the main functions of the decision support system:

a) To develop an evaluation model for assessing applicants' ability to study IT programmes;

b) To develop an evaluation model for assessing activity effectiveness to select an appropriate activity set for applicants potentially able to study a particular programme;

3) To undertake an experimental study with the help of DSS for selection of some cooperation forms between YuTI TPU and applicants potentially able to study IT programmes.

The study stages are:

1) To study a decision support process for selecting cooperation forms between higher educational institutions and potential students;

2) To develop an author conception of the decision support system for selecting cooperation forms between higher educational institutions and potential students;

3) To develop an evaluation model for assessing applicants' ability to study IT programmes;

4) To develop methods for assessing activity effectiveness to select an appropriate activity set for applicants potentially able to study a particular programme;

5) To organize expert evaluation of professional-oriented activity effectiveness;

6) To test YuTI TPU applicants for assessing their ability to study IT programmes;

7) To select some activities for applicants able to study IT programmes.

The research is done in 2013-2014. As a result we have a new author decision making support conception for selection of cooperation forms between a higher educational institution and a potential student which includes five interrelated stages. It is developed an author evaluation model for assessing applicants' ability to study technical programmes, an author methodology for assessing professional-oriented activity effectiveness to select an appropriate activity set for applicants potentially able to study a particular programme.

\section{DISCUSSION OF THE RESEARCH OUTCOMES. DECISION SUPPORT SYSTEM MODELING FOR SELECTION OF COOPERATION FORMS BETWEEN A HIGHER EDUCATIONAL INSTITUTION AND A POTENTIAL STUDENT.}

\section{A. Decision support system conception development for selecting cooperation forms between a higher educational institution and a potential student.}

After analyzing decision making practice which deals with activity selection for potential students at higher educational institutions we state basic stages for selecting cooperation forms between a higher educational institution and a potential student with a glance to their individual peculiarities:

1) Assessment of applicants' ability to study University programmes. After considering information about applicants and their test results we assess each applicant's ability to study each University programme.

2) Activity (cooperation form) list development for each programme. The list is developed on the basis of external and internal University environment. It is useful to classify all possible cooperation forms (activities) (group by group) to minimize an assessed alternative number. It is also necessary to classify activities according to their potential to be used for applicants to particular programmes.

3) Expert evaluation of activities according to some criteria. In view of poor structuring of the aim and some uncertainty in a decision making process it is necessary to appeal to experts for assessing activity effectiveness. Evaluation criteria are qualitative and quantitative indicators and characteristics, for example: reach to target audience, activity expenses, quality of activity, etc.

4) Activity list development for applicants able to study particular programmes.

5) Activity effectiveness monitoring. Activity effectiveness rating is done on the basis of matriculation data and information about applicants' participation in University activities.

Decision support system is a computer system, the aim of which is to ensure data and tool support for decision making process based on subject area analysis.

For the decision support system we develop some mathematical models which reflect cause-effect relations between decision making conditions. In system application process these models can be corrected by adding new connections, extending existing ones, changing or deleting those connections which are not important any more (because of some University reorganizations).

It is necessary to note that in Russia and abroad there are some research works connected with the development of aim particular aspects: potential students' monitoring, activity planning and control, etc. [7-9]. Nevertheless there is no methodological base for selecting cooperation forms between a higher educational institution and a potential student; there are no information support tools for this process.

In that context we have a problem of the development of model and tool decision making support for selecting cooperation forms between a higher educational institution and a potential student; with their help it is possible to evaluate cooperation forms with a glance to applicants' individual peculiarities, monitor and assess activity effectiveness.

In Figure 1 there is a concept model of an information decision support system for selecting cooperation forms between a higher educational institution and a potential student. 5 main functions are realized in DSS; they are: 
- assessment of students' ability to study programmes;

- activity (cooperation form) list development for each programme;

- experimental activity assessment according to the criteria;

- selection of activities for students able to study a particular programme;

- monitoring of activity effectiveness.

The decision support system has three main components: data subsystem, method and model subsystem, and software subsystem. Data subsystem has information about applicants, psychological test information and information about YuTI TPU cooperation forms (activities). Method and model subsystem has mathematical models which can be available for users. Software subsystem ensures the interaction between a system user, data base and model base. It also has a comfortable interface which supports a dialogue between a user and DSS.

\section{B. Software support for DSS main functions. Model development for assessing applicants' ability to study IT programmes}

In DSS we use the method of discriminant analysis for assessing applicants' ability to study. All YuTI TPU programmes are divided into several groups with similar requirements to applicants' individual peculiarities being necessary for studying IT, technical, and humanitarian programmes. We have a separate research to develop a model for assessing applicants' ability to study IT programmes. The research goal is to develop a mathematical model which with the help of psychological tests allows identifying applicants able to study IT programmes.

The research comprises two stages:

- Indicator testing and selection for evaluation of professionally valuable personal qualities;

- Mathematical model development with the help of the discriminant analysis method based on applicants' tests.

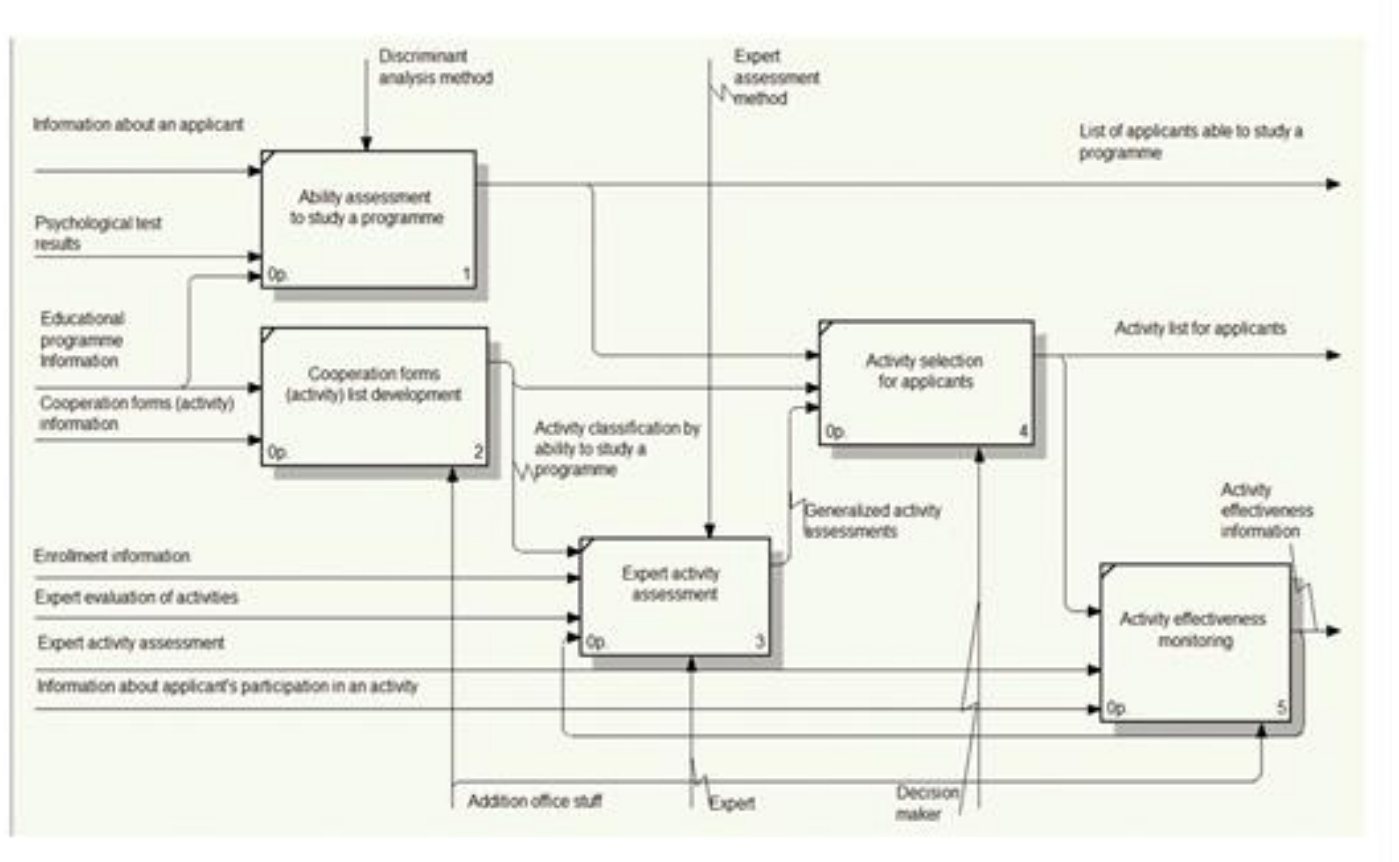

Fig. 1. - DSS functional diagram about cooperation forms between a higher educational institution and a potential student

At the first stage of our research we have tested 127 people (they are secondary school graduates from our city, technical school students) involved into professional-oriented activities of our Institute. We have also tested the students studying YuTI TPU IT programmes to specify a peculiarity set which characterizes students able to study IT programmes.

Our experts have chosen two tests for this research: "Differential Diagnostic Form" (DDF, E.A. Klimova) and "Constructible Man Drawing out of Geometric Objects". These methods do not take much time and give good results for identifying personality types and potential students' ability to study a particular programme.
Evaluation is done according to the following scales:

X1 - Man - nature;

$\mathrm{X} 2$ - Man - engineering;

X3 - Man - man;

X4 - Man - semiotic system;

X5 - Man - imagery;

X6 - Boss;

X7 - Responsible officer; 
X8 - Worrywart;

X9 - Scientist;

$\mathrm{X} 10$ - Intuitive;

X11 - Inventor, constructor, and artist;

X12 - Emotive.

Then we have chosen a peculiarity set which characterizes students able to study IT programmes. These people have high values in the following scales: "X2 - Man - engineering", "X4 - Man - semiotic system", "X7 - Responsible officer", "X9 Scientist", "X5 - Man - imagery", "X11 - Inventor, constructor, and artist". According to peculiarity characteristics it is possible to conclude that these people have abilities to work in a technical area. The characteristic "Man engineering" says the following: people like modeling, they are good at engineering, can create, use and repair cars, mechanisms, and devices. The characteristic "Man - semiotic system" says that man has ability to calculate, draw, design schemes, and systematize data. These people are good at statistics, economics, and software engineering. Professions of this type are connected with information processing. The characteristic "Responsible officer" says that these people are focused on "real work". The characteristic "Scientist" says that these people are with "conceptual brains", they tend to work out their own theories. They think over their conduct, and they are well balanced. The characteristics "Man - imagery" and "Inventor, constructor, and artist" characterize people with good imagination and space viewing. They are often interested in technical, intellectual, and artistic creation. The characteristics connected with art are important as for technical so for humanitarian professions. People from this group have low values in the following scales: X1 - Man - nature, X12 Emotive, X3 - Man - man, X8 - Worrywart. It means that these people have some difficulties in studying humanitarian programmes and working in the areas connected with crop science, animal breeding and forest management. These people do not usually work in the areas of bringing-up children, medical attendance (doctors, medical assistance), society and state protection (lawyers, policemen, and military men), public services (salespeople, hairdressers).

Then we have developed a mathematical model based on chosen characteristics with the help of the discriminant analysis method. We have used the data of the students studying IT programmes.

In diagnostics and prognosis of different human states specialists often use methods based on the image discrimination theory. Prognosis procedure includes classification of two or more general aggregates and obtaining a rule, which allows associating a new element (object) according to some criteria with one from the aggregate classes. To solve such problems it is used the method of discriminant analysis.

Discriminant analysis is a part of multivariate statistical analysis which contains statistical classification methods of multivariate observations according to one of several categories or aggregates. One variation of discriminant analysis is application of Firsh's classifying (discriminant) functions.
They are used for identifying diagnostic accuracy of multivariate observation classification.

Weight coefficients of discriminant functions are defined according to the formula(1):

$$
w_{i}=S^{-1} m_{i},(i=1, k)
$$

where $S$ is covariance matrix of a diagnostic class;

$m i$ is a means i vector of a diagnostic class;

$k$ is a quantity of classes.

Threshold values are calculated in the following way(2):

$$
\omega_{0 i}=-\frac{1}{2} w_{i}^{T} m_{i}+\ln P_{i}, i=1, k
$$

where $P i$ is a prior probability of $i$ class.

The diagnostic rule with the use of discriminant functions is as follows: the object $\mathrm{x}$ refers to $i$ class if the condition holds true(3):

$$
g_{i}(x)=\max _{j=1, k} g_{j}(x)
$$

where $g_{i}(x)=w_{i}^{T} x-\omega_{0 i}$.

The method of discriminant analysis is realized with the help of the statistical programme package "Statgraphics plus for Windows". It is expected that the result is one of the following: 1 - successful IT programme students, 2 - students with ordinary abilities to study technical programmes, and $3-$ students without definite abilities to study technical programmes.

We form these three groups according to the following rule: students with high values in the scales X2, X4, X7, X9, X5, $\mathrm{X} 11$ are able to study IT programmes (for example, "Application Informatics"); students with average values in the scales X2, X4, X7, X9, X5, X11 are in the second group; students with low values in the scales X2, X4, X7, X9, X5, $\mathrm{X} 11$ and high values in the scales $\mathrm{X} 3, \mathrm{X} 10, \mathrm{X} 1, \mathrm{X} 12, \mathrm{X} 6, \mathrm{X} 8$ are in the third group.

We have got the following discriminant functions:

$\mathrm{g} 1=-76,37+5,07 * \mathrm{X} 1+10,01 * \mathrm{X} 2+0,60 * \mathrm{X} 3+9,40 * \mathrm{X} 4+$ $6,53 * \mathrm{X} 5+10,31 * \mathrm{X} 6-1,33 * \mathrm{X} 7-2,10 * \mathrm{X} 8+4,57 * \mathrm{X} 9+$ $5,62 * X 10+2,30 * X 11+3,24 * X 12$

$\mathrm{g} 2=-60,91+5,88 * \mathrm{X} 1+8,06 * \mathrm{X} 2+0,72 * \mathrm{X} 3+6,98 * 4+$ $7,06 * \mathrm{X} 5+8,09 * \mathrm{X} 6+0,45 * \mathrm{X} 7+0,41 * \mathrm{X} 8+5,30 * \mathrm{X} 9+$ $4,06 * \mathrm{X} 10+2,22 * \mathrm{X} 11+2,68 * \mathrm{X} 12$

$\mathrm{g} 3=-49,71+6,58 * \mathrm{X} 1+6,03 * \mathrm{X} 2+0,60 * \mathrm{X} 3+5,29 * \mathrm{X} 4+$ $6,67 * \mathrm{X} 5+6,03 * \mathrm{X} 6+2,03 * \mathrm{X} 7-0,17 * \mathrm{X} 8+5,63 * \mathrm{X} 9+$ $3,20 * \mathrm{X} 10+1,41 * \mathrm{X} 11+2,67 * \mathrm{X} 12$.

Realizing discriminant method analysis we have defined diagnostic accuracy and classifying functions on the basis of which the decision rule is developed. You can see student diagnostic accuracy in Table 1. 
TABLE I. CORRECT TEST RESULTS FOR THREE GROUPS

\begin{tabular}{|c|c|}
\hline Group number & Diagnostic accuracy \\
\hline 1 & $94,59 \%$ \\
2 & $87,50 \%$ \\
3 & $85,71 \%$ \\
\hline
\end{tabular}

The Table 1 shows that diagnostic accuracy for the first group (successful IT-technical programme students) is $94.59 \%$, for the second one (students with ordinary abilities to study technical and humanitarian programmes) $-87.50 \%$, for the third group (students without definite abilities to study technical programmes) $-85.71 \%$. The total percentage of cases with correct diagnostics is quite high $-90.24 \%$. That is why it is reasonable to use developed discriminant functions for identifying potential students' ability to study technical and IT programmes [10].

With the help of the decision rule we can identify potential students able to study technical and IT programmes. We can use discriminant analysis coefficients and numeric values of calculated characteristics to develop discriminant functions for every student.

At the result of the research we have formed an indicator set and got a mathematical model allowing selecting potential students for IT programmes.

\section{Model development for activity effectiveness assessment to select an activity set for potential students able to study a particular programme}

Decision making process analysis concerning selection of cooperation forms between a higher educational institution and a potential student shows that activity effectiveness assessment is usually done by experts. Experts are as University stuff (people from departments, admission offices, executives) so external invited specialists.

Experts receive a cooperation form list based on activity plans and held brainstorming sessions. Experts also need activity effectiveness information and admission results for the previous years. An expert makes a decision on the basis of received information and their experience assessing activity effectiveness according to the criteria. We use a weighted sum method for indicator folding.

The expert assesses each criterion with maximum 5 points ( 1 is low indicator value, 5 is high indicator value, and vice versa for the indicator "Activity costs"). Assessment criterion importance is defined by weight coefficients. Generalized activity assessments are calculated by the formula(4):

$$
O_{j}=\sum_{i=1}^{n} A_{i j} \cdot W_{i}
$$

where $O_{j}$ is generalized expert assessment of $j$-activity effectiveness;

$A_{i j}$ is expert assessment of $j$-activity by $i$-criterion;

$W_{i}$ is indicator weight; $\sum_{i=1}^{n} W_{i}=1$
D. Experimental study for selecting cooperation forms between YUTI TPU and applicants potentially able to study IT programmes with the help of DSS

We have done an experimental study for selecting cooperation forms between YuTI TPU and applicants potentially able to study IT programmes on the basis of our DSS conception, decision making models, and software.

We have loaded applicant database with their personal information and psychological test results. Then we have attributed each student to one of YuTI TPU programmes on the basis of the developed model for assessing potential students' ability to study IT programmes (see 3.2.1 part of the paper).

TABLE II. ACTIVITY CLASSIFICATION BY POTENTIAL STUDENTS ABILITY TO STUDY YUTI TPU PROGRAMMES.

\begin{tabular}{|c|c|c|c|c|}
\hline \multirow[t]{2}{*}{ № } & \multirow{2}{*}{$\begin{array}{lr}\text { YuTI } & \text { TPU } \\
\text { profession } & \text { oriented } \\
\text { activities } & \end{array}$} & \multicolumn{3}{|c|}{ YuTI TPU programme groups } \\
\hline & & 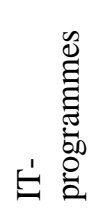 & 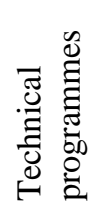 & 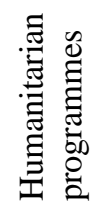 \\
\hline 1. & $\begin{array}{l}\text { Work } \\
\text { educational } \\
\text { institutions }\end{array}$ & + & + & + \\
\hline 2. & $\begin{array}{l}\text { Olympiad } \\
\text { management }\end{array}$ & + & + & + \\
\hline 3. & INTERNET & + & + & + \\
\hline 4. & $\begin{array}{l}\text { Situational game } \\
\text { «VEKTOR» } \\
\text { Management }\end{array}$ & + & - & - \\
\hline 5. & $\begin{array}{l}\text { Training courses } \\
\text { management for } \\
\text { state uniform } \\
\text { examination }\end{array}$ & + & + & + \\
\hline 6. & $\begin{array}{l}\text { Open day for school } \\
\text { graduates }\end{array}$ & + & + & + \\
\hline 7. & $\begin{array}{l}\text { Work with mass } \\
\text { media }\end{array}$ & + & + & + \\
\hline 8. & $\begin{array}{l}\text { City IT Olympiad } \\
\text { Management }\end{array}$ & + & - & - \\
\hline 9. & $\begin{array}{l}\text { Professional } \\
\text { oriented } \\
\text { though } \\
\text { regions }\end{array}$ & + & + & - \\
\hline 10 & $\begin{array}{l}\text { Work with potential } \\
\text { students' parents }\end{array}$ & + & + & + \\
\hline
\end{tabular}

We have analyzed YuTI TPU activity plans for work with potential students for last 3 years. We have selected the most important activities for admission to YuTI TPU. On the basis 
of these activities we have done an activity structure for admission to YuTI TPU.

Then we have classified the activities by their potential to be used in work with applicants able to study YuTI TPU IT, technical or humanitarian programmes. You can see results in Table 2

Then we have done expert activity effectiveness assessment. It is formed the following criterion list for activity effectiveness assessment:

1) YuTI TPU programme coverage.

2) Activity target (for example, to increase physics knowledge).

3) Activity costs (time, finance and material).

4) Activity quality (YuTI TPU activity quality level).

5) Activity effectiveness (the main activity effect is filling an application to YuTI TPU).

The expert can use database about held activities for last three years.

An executive secretary of the admission office has appointed assessment criteria importance weights (Table 3).

TABLE III. WEIGHT DISTRIBUTION

\begin{tabular}{|c|c|c|c|c|}
\hline $\mathrm{W}_{1}$ & $\mathrm{~W}_{2}$ & $\mathrm{~W}_{3}$ & $\mathrm{~W}_{4}$ & $\mathrm{~W}_{5}$ \\
\hline 0,25 & 0,17 & 0,18 & 0,2 & 0,2 \\
\hline
\end{tabular}

You can see generalized activity assessment results by the criteria in Table 4.

TABLE IV

GENERALIZED ASSESSMENT RESULTS

\begin{tabular}{|c|c|c|c|c|c|c|c|}
\hline \multirow[b]{2}{*}{ № } & \multirow[b]{2}{*}{ Activity list } & \multicolumn{5}{|c|}{ Criteria list, $K$} & \multirow[b]{2}{*}{ 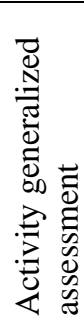 } \\
\hline & & $\mathrm{K}_{1}$ & $\mathrm{~K}_{2}$ & $\mathrm{~K}_{3}$ & $\mathrm{~K}_{4}$ & $\mathrm{~K}_{5}$ & \\
\hline 1 & $\begin{array}{l}\text { Work with } \\
\text { educational } \\
\text { institutions }\end{array}$ & 1,25 & 0,85 & 0,36 & 0,8 & 1 & 4,26 \\
\hline 2 & $\begin{array}{l}\text { Olympiad } \\
\text { management }\end{array}$ & 1 & 0,85 & 0,18 & 1 & 0,8 & 3,83 \\
\hline 3 & Internet & 1 & 0,68 & 0,72 & 0,4 & 1 & 3,8 \\
\hline 4 & $\begin{array}{l}\text { Situational } \\
\text { game } \\
\text { «VEKTOR» } \\
\text { Management }\end{array}$ & 0,75 & 0,85 & 0,18 & 1 & 0,8 & 3,58 \\
\hline 5 & $\begin{array}{l}\text { Training } \\
\text { courses } \\
\text { management }\end{array}$ & 1,25 & 0,51 & 0,54 & 1 & 0,6 & 3,9 \\
\hline
\end{tabular}

\begin{tabular}{|l|l|l|l|l|l|l|l|}
\hline & $\begin{array}{l}\text { for state } \\
\text { uniform } \\
\text { examination }\end{array}$ & & & & & & \\
\hline 6 & $\begin{array}{l}\text { Open day for } \\
\text { school } \\
\text { graduates }\end{array}$ & 1,25 & 0,51 & 0,54 & 0,8 & 0,8 & 3,9 \\
\hline 7 & $\begin{array}{l}\text { Work with } \\
\text { mass media }\end{array}$ & 0,5 & 0,34 & 0,72 & 0,2 & 0,2 & 1,96 \\
\hline 8 & $\begin{array}{l}\text { City IT } \\
\text { Olympiad } \\
\text { Management }\end{array}$ & 0,75 & 0,85 & 0,18 & 1 & 0,8 & 3,58 \\
\hline 9 & $\begin{array}{l}\text { Professional } \\
\text { oriented trips } \\
\text { though some } \\
\text { regions }\end{array}$ & 0,25 & 0,17 & 0,18 & 0,6 & 0,4 & 1,6 \\
\hline 10 & $\begin{array}{l}\text { Work with } \\
\text { potential } \\
\text { students' } \\
\text { parents }\end{array}$ & 0,5 & 0,17 & 0,72 & 0,8 & 0,6 & 2,79 \\
\hline
\end{tabular}

The generalized activity assessment results allow selecting six most effective cooperation forms (activities) for potential students able to study IT programmes:

- Work with educational institutions;

- Training courses management for state uniform examination;

- Open day for school graduates;

- Olympiad management;

- INTERNET;

- City IT Olympiad Management.

We have realized these activities in 2015 for potential students able to study IT programmes. Enrollment company result analysis shows:

- $92 \%$ of potential students who were involved into YuTI TPU activities decided to enter IT programmes;

- quantity of application forms to IT programmes increased by $13 \%$;

- average enrollment mark in state uniform examination increased by $27 \%$ for IT programmes that increases students' qualitative characteristics.

\section{CONCLUSION}

In the result we have given enough reasons for decision support system development for selection of cooperation forms between a higher educational institution and a potential student. We have defined main stages for selecting cooperation forms between a higher educational institution and a potential student on the basis of system analysis of decision practices existing at Universities. We have developed the conception of an automated decision support system for selecting cooperation 
forms between a higher educational institution and a potential student on the basis of input and output information analysis. We have developed software for DSS main functions: 1. Evaluation model for assessing applicants' ability to study IT programmes on the basis of a discriminant analysis method; 2. Evaluation model for assessing activity effectiveness to select an appropriate activity set for applicants potentially able to study a particular programme. For approbation of the proposed approach with the help of DSS we have done an experimental study to select some cooperation forms between YuTI TPU and applicants potentially able to study IT programmes. In the result we have formed an activity effectiveness list for potential students able to study IT programmes. Realization of these activities allowed increasing qualitative and quantitative characteristics of applicants' enrollment to YuTI TPU IT programmes.

\section{REFERENCES}

[1] P. Gibbs, \& A. Dean, "Do higher education institutes communicate trust well? Journal of Marketing for Higher Education", 2015, doi:10.1080/08841241.2015.1059918 Article in press

[2] S. J. Brown, B. N. Sharma, L. Wakeling, M. Naiker, S. Chandra, R. D. Gopalan, \& J. C. Doshi,, \& B. Trivedi, "Decision support system using DMAIC for academic scheduling: ICT in education support activities". Paper presented at the Proceedings - 2013 IEEE 5th International Conference on Technology for Education, T4E 2013, 2013,p. 73-75. doi:10.1109/T4E.2013.26

[3] V. L. Bibik, D. P. Iljyashchenko, "Practically oriented training of engineers", «ICAEM 2014» International conference on advanced education and management: proceedings, Beijing, January 4-5, 2014. Beijing, China: IALE, 2014 - p. 55-60
[4] A. Urintsov, V. Dik, \& N. Dneprovskaya, " Individual learning trajectories as a key educational tool in the information society", 2014, doi:10.3233/978-1-61499-405-3-652

[5] V. B. Bilimoria, "Quantifying attitude to chemistry in students at the university of the south pacific", Chemistry Education Research and Practice, 15(2), 2014, 184-191. doi:10.1039/c3rp00155e

[6] B. Shulruf, \& J. Shaw, "How the admission criteria to a competitiveentry undergraduate programme could be improved". Higher Education Research and Development, 34(2), 2015, 397-410. doi:10.1080/07294360.2014.956693

[7] V. Kostoglou, N. Ploskas, M. Vassilakopoulos, \& V. Tsantopoulou, "Analysis and design of a web-based decision support system for choosing higher education studies". Yugoslav Journal of Operations Research, 24(3), 2014, 399-414. doi:10.2298/YJOR140411025K

[8] O. Ibrahim, D. Sundgren, \& A. Larsson, "An integrated decision support system framework for strategic planning in higher education institutions", 2014, doi:10.1007/978-3-319-07179-4

[9] A.A. Zakharova, A.N. Lazareva, O.Y. Zorina \& V.V. Ostanin (), "Information decision support system for selecting an educational programme" Modern problems of Science and Education, 3, 2014; http://www.science-education.ru/117-13814

[10] O.N. Fisochenko \& E.A. Lyakhova, "Creation of professional orientation model on the basis of the discriminant analysis"// Modern problems of Science and Education, 6, 2013; http://www.scienceeducation.ru/ru/article/view?id=10790 